\title{
Double diffusive magnetohydrodynamic squeezing flow of nanofluid between two parallel disks with slip and temperature jump boundary conditions
}

\author{
M. G. Sobamowo ${ }^{a, *}$, A. T. Akinshilo ${ }^{a}$ \\ ${ }^{a}$ Department of Mechanical Engineering, University of Lagos, Akoka-Yaba, Lagos, Nigeria
}

Received 28 May 2017; accepted 11 December 2017

\begin{abstract}
In this paper, double diffusive squeezing unsteady flow of electrically conducting nanofluid between two parallel disks under slip and temperature jump condition is analyzed using the homotopy perturbation method. The obtained solutions from the analysis are used to investigate the effects of the of Brownian motion parameter, thermophoresis parameter, Hartmann number, Lewis number and pressure gradient parameters, slip and temperature jump boundary conditions on the behavior of the nanofluid. Also, the results of the homotopy perturbation method are compared to the results in the literature and good agreements are established. This study is significant to the advancements of nanofluidics such as energy conservation, friction reduction and micro mixing biological samples.
\end{abstract}

(C) 2017 University of West Bohemia. All rights reserved.

Keywords: double diffusive, squeezing flow, nanofluid, slip effects, parallel disk, homotopy perturbation method

\section{Introduction}

The study of fluid flow between parallel surfaces has generated wide research interests over the years due to its increasing application in the field of science and engineering. Fluid flow in parallel medium such as disks has useful applications in manufacturing industries, power transmission equipment amongst others due to parallel surfaces in relative motion. In efforts to study fluid flow between parallel surfaces, Mustafa et al. [25] investigated the heat and mass transfer between parallel plates undergoing unsteady squeezing fluid flow while Hayat et al. [11] presented the squeezing flow of second grade fluid between parallel disk in the presence of magnetic field. In another work, Domairry and Aziz [3] applied the homotopy perturbation method to study the effect of suction and injection on MHD squeeze flow between parallel disks. The squeezing flow viscous fluid flow between plates under unsteady condition was analyzed by Siddiqui et al. [47]. Rashidi et al. [28] explored analytical solutions to study unsteady squeezing flow between parallel plates. Khan and Aziz [20] presented a study on the flow of nanofluid between parallel plates due to natural convection. Shortly after, Khan and Aziz [19] analyzed double diffusive natural convective boundary layer fluid flow through porous media saturated with nanofluid while Kuznestov and Nield [21] also studied nanofluid flow between parallel plates but with natural convective boundary layer. Hashimi et al. [10] developed analytical solutions in studying squeezing fluid flow of nanofluid. The effect of stretching sheet wall problem adopting natural convective boundary conditions was investigated by Yao et al., Kandasamy et al., Makinde and Aziz [18, 22, 50]. However, in recent past, the effects of slip effect on fluid

\footnotetext{
*Corresponding author. Tel.: +234 70347174 17, e-mail: mikegbeminiyi@ gmail.com. https://doi.org/10.24132/acm.2017.367
} 


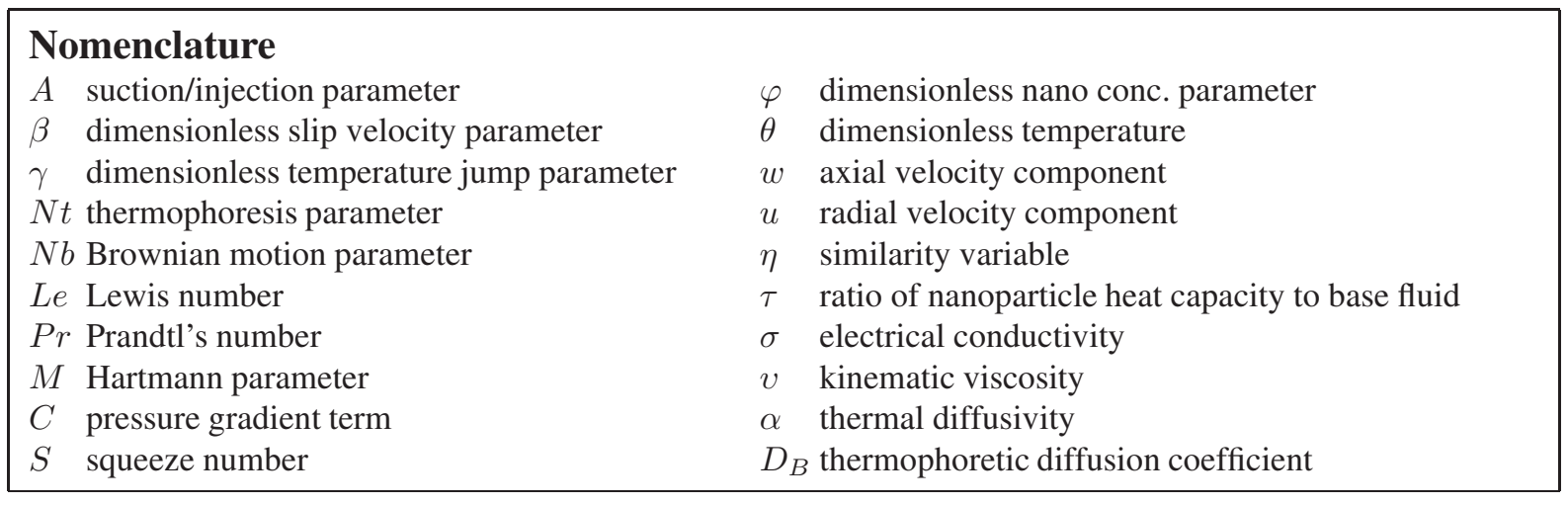

flow have been considered by many researchers $[1,3-6,8,17,23,27,49]$ due to its significance to most practical fluid flow situations. When flow system characteristics size is small or low flow pressure, the assumption of no slip boundary condition becomes insufficient and inadequate in predicting the flow behavior under such scenario. Therefore, additional boundary conditions are required to adequately predict the low flow pressure or low system characteristics size. Such slip boundary condition was first initiated by Navier [26] upon which other researchers have built $[2,24]$. Most of the above reviews have been limited to the analysis of squeezing flow under no slip and no temperature jump boundary conditions. Moreover, most of the nonlinear fluid flow and heat transfer problems have solved with different numerical and semi-analyticalnumerical or approximate analytical methods [29-46]. However, the development of analytical solutions by some of the approximate analytical methods such as Adomian decomposition method, homotopy analysis method, variation iteration methods for the flow process often involved complex mathematical analysis leading to analytic expression involving a large number terms. In practice, analytical solutions with large number of terms and conditional statements for the solutions are not convenient for use by designers and engineers $[9,48]$. Also, in such methods, the search for a particular value that will satisfy the other end boundary condition(s) necessitated the use of software and such always results in additional computational cost in the generation of solution to the problem. Consequently, in many research works, recourse has been made to numerical methods in solving the problems. However, in the class of the newly developed approximate analytical methods, homotopy perturbation method is considered to relatively simple with fewer requirements for mathematical rigour or skill. Homotopy perturbation method (HPM) gives solutions to nonlinear integral and differential equations without linearization, discretization, closure, restrictive assumptions, perturbation, approximations, round-off error and discretization that could result in massive numerical computations. It provides excellent approximations to the solution of non-linear equation with high accuracy. Moreover, the need for small perturbation parameter as required in traditional PMs, the difficulty in determining the Adomian polynomials, the rigour of the derivations of differential transformations or recursive relation as carried out in DTM, the lack of rigorous theories or proper guidance for choosing initial approximation, auxiliary linear operators, auxiliary functions, auxiliary parameters, and the requirements of conformity of the solution to the rule of coefficient ergodicity as done in HAM, the search Lagrange multiplier as carried in VIM, and the challenges associated with proper construction of the approximating functions for arbitrary domains or geometry of interest as in Galerkin weighted residual method (GWRM), least square method (LSM) and collocation method (CM) are some of the difficulties that HPM overcomes. The results of HPM are completely reliable and physically realistic and unlike the other approximate analytical methods, it does not involve the search for a particular value that will satisfy the other end 
boundary condition(s) [12-16]. Therefore, in this work, homotopy perturbation method is used to study the slip effects of squeezing nanofluid flow through two parallel disks under magnetic field with pressure gradient. The analytical solution of the homotopy perturbation method is used to investigate the effects of various flow parameters with the effects discussed in detail.

\section{Model development and analytical solution}

Consider a nanofluid that flows axisymmetrically through parallel disks as shown in Fig. 1. The upper disk is moving towards the stationary lower disks under uniform magnetic field strength applied perpendicular to disk. The fluid conducts electrical energy as it flows unsteadily under magnetic force field. The fluid structure is everywhere in thermodynamic equilibrium and the plate is maintained at constant temperature.

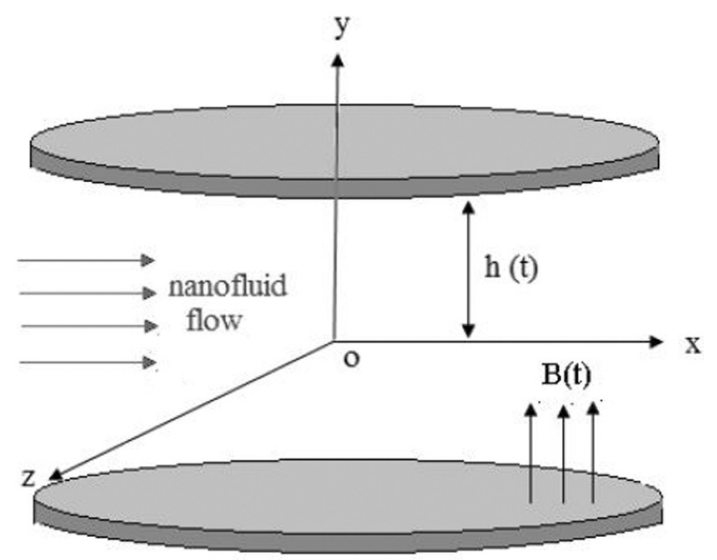

Fig. 1. Physical model of problem [6]

The details of the governing equation and non-dimensional parameters have been described in [6] which can be introduced under stated assumptions as:

$$
\begin{aligned}
& \frac{\partial u}{\partial r}+\frac{u}{r}+\frac{\partial w}{\partial z}=0 \\
& \frac{\partial u}{\partial t}+u \frac{\partial u}{\partial r}+w \frac{\partial u}{\partial z}=-\frac{1}{\rho_{n f}} \frac{\partial p}{\partial r}+v_{n f}\left(\frac{\partial^{2} u}{\partial r^{2}}+\frac{\partial^{2} u}{\partial z^{2}}+\frac{1}{r} \frac{\partial u}{\partial r}-\frac{u}{r^{2}}\right)-\frac{\sigma B^{2}(t)}{\rho_{n f}} u \\
& \frac{\partial w}{\partial t}+u \frac{\partial w}{\partial r}+w \frac{\partial w}{\partial z}=-\frac{1}{\rho_{n f}} \frac{\partial p}{\partial z}+v_{n f}\left(\frac{\partial^{2} w}{\partial r^{2}}+\frac{\partial^{2} w}{\partial z^{2}}+\frac{1}{r} \frac{\partial w}{\partial r}\right), \\
& \frac{\partial T}{\partial t}+u \frac{\partial T}{\partial r}+w \frac{\partial T}{\partial z}=\alpha_{n f}\left(\frac{\partial^{2} T}{\partial r^{2}}+\frac{1}{r} \frac{\partial T}{\partial r}+\frac{\partial^{2} T}{\partial z^{2}}\right)+ \\
& \tau_{n f}\left[D_{B}\left(\frac{\partial c}{\partial r} \frac{\partial T}{\partial r}+\frac{\partial c}{\partial z} \frac{\partial T}{\partial z}\right)+\frac{D_{T}}{T_{m}}\left\{\left(\frac{\partial T}{\partial r}\right)^{2}+\left(\frac{\partial T}{\partial z}\right)^{2}\right\}\right], \\
& \frac{\partial c}{\partial t}+u \frac{\partial c}{\partial r}+w \frac{\partial c}{\partial z}=D_{B, n f}\left(\frac{\partial^{2} c}{\partial r^{2}}+\frac{1}{r} \frac{\partial c}{\partial r}+\frac{\partial^{2} c}{\partial z^{2}}\right)+\frac{D_{T}}{T_{m}}\left(\frac{\partial^{2} T}{\partial r^{2}}+\frac{1}{r} \frac{\partial T}{\partial r}+\frac{\partial^{2} T}{\partial z^{2}}\right) .
\end{aligned}
$$

The relevant boundary conditions are given as

$$
\begin{aligned}
u(0) & =-\beta_{1} \frac{\partial u}{\partial z}, \quad w(0)=\frac{w_{0}}{\sqrt{1-\alpha t}}, \quad T(0)=-\gamma_{1} \frac{\partial T}{\partial z}+T_{w}, \quad c(0)=c_{w}, \\
u & =-\beta_{1} \frac{\partial u}{\partial z}, \quad w=w_{h}\left(\frac{\partial h}{\partial t}\right), \quad T=\gamma_{1} \frac{\partial T}{\partial z}+T_{h}, \quad c=c_{h} \text { at } z=h(t) .
\end{aligned}
$$


Using the following dimensionless quantities

$$
\begin{aligned}
A & =\frac{w_{0}}{\alpha H}, \quad \beta=\frac{\beta_{1}}{H \sqrt{1-\alpha t}}, \quad \gamma=\frac{\gamma_{1}}{H \sqrt{1-\alpha t}}, \quad N t=\frac{\tau D_{B}\left(T_{w}-T_{h}\right)}{v}, \\
N b & =\frac{\tau D_{B}\left(c_{w}-c_{h}\right)}{v}, \quad L e=\frac{v}{D_{B}}, \quad \operatorname{Pr}=\frac{v}{\alpha}, \quad M=H B_{0} \sqrt{\frac{\sigma}{\mu}}, \\
C & =\left(\frac{\alpha H}{\mu_{f} v_{f}}\right)\left(\frac{\partial p}{\partial z}\right), \quad S=\frac{\alpha H^{2}}{2 \nu}, \quad \varphi=\frac{c-c_{h}}{c_{w}-c_{h}}, \quad \theta=\frac{T-T_{h}}{T_{w}-T_{h}}, \\
w & =\frac{\alpha H}{2 \sqrt{1-\alpha t}} f(\eta), \quad u=\frac{\alpha r}{2(1-\alpha t)} f^{\prime}(\eta), \quad \eta=\frac{z}{H \sqrt{1-\alpha t}}, \quad \tau=\frac{(\rho c)_{p}}{(\rho c)_{f}} .
\end{aligned}
$$

The dimensionless equations are given as

$$
\begin{array}{r}
\frac{\mathrm{d}^{4} f}{\partial \eta^{4}}-S\left(\eta \frac{\mathrm{d}^{3} f}{\mathrm{~d} \eta^{3}}+3 \frac{\mathrm{d}^{2} f}{\mathrm{~d} \eta^{2}}+f \frac{\mathrm{d} f}{\mathrm{~d} \eta}-2 \frac{\mathrm{d} f}{\mathrm{~d} \eta} \frac{\mathrm{d}^{3} f}{\mathrm{~d} \eta^{3}}\right)-M^{2} \frac{\mathrm{d}^{2} f}{\mathrm{~d} \eta^{2}} \\
=C, \\
\frac{\mathrm{d}^{2} \theta}{\mathrm{d} \eta^{2}}+\operatorname{Pr} S\left(2 f \frac{\mathrm{d} \theta}{\mathrm{d} \eta}-\eta \frac{\mathrm{d} \theta}{\mathrm{d} \eta}\right)+\operatorname{Pr}\left(N b \frac{\mathrm{d} \theta}{\mathrm{d} \eta} \frac{\mathrm{d} \varphi}{\mathrm{d} \eta}+N t\left(\frac{\mathrm{d} \theta}{\mathrm{d} \eta}\right)^{2}\right)=0 \\
\frac{\mathrm{d}^{2} \varphi}{\mathrm{d} \eta^{2}}+L e S(2 f-\eta) \frac{\mathrm{d} \theta}{\mathrm{d} \eta}+\frac{N t}{N b} \frac{\mathrm{d}^{2} \varphi}{\mathrm{d} \eta^{2}}=0
\end{array}
$$

and the dimensionless boundary conditions are given as

$$
\begin{aligned}
& f(0)=A, \quad \frac{\mathrm{d} f(0)}{\mathrm{d} \eta}=-\beta \frac{\mathrm{d}^{2} f(0)}{\mathrm{d} \eta^{2}}, \quad f(1)=\frac{1}{2}, \quad \frac{\mathrm{d} f(1)}{\mathrm{d} \eta}=\beta \frac{\mathrm{d}^{2} f(1)}{\mathrm{d} \eta^{2}} \\
& \theta(0)=1-\gamma \frac{\mathrm{d} \theta}{\mathrm{d} \eta}, \quad \theta(1)=\gamma \frac{\mathrm{d} \theta}{\mathrm{d} \eta} \\
& \varphi(0)=0, \quad \varphi(1)=0 .
\end{aligned}
$$

\section{Method of solution by homotopy perturbation method}

The comparative advantages and the provision of acceptable analytical results with convenient convergence and stability [12-16] coupled with total analytic procedures of homotopy perturbation method compel us to consider the method for solving the system of nonlinear differential equations in (9)-(11).

\subsection{The basic idea of homotopy perturbation method}

In order to establish the basic idea behind homotopy perturbation method, consider a system of nonlinear differential equations given as

$$
A(U)-f(r)=0, \quad r \in \Omega
$$

with the boundary conditions

$$
B\left(u, \frac{\partial u}{\partial \eta}\right)=0, \quad r \in \Gamma
$$

where $A$ is a general differential operator, $B$ is a boundary operator, $f(r)$ a known analytical function and $\Gamma$ is the boundary of the domain $\Omega$. 
The operator $A$ can be divided into two parts, which are $L$ and $N$, where $L$ is a linear operator, $N$ is a non-linear operator. Eq. (15) can be therefore rewritten as follows

$$
L(u)+N(u)-f(r)=0 .
$$

By the homotopy technique, a homotopy $U(r, p): \Omega \times[0,1] \rightarrow \mathbb{R}$ can be constructed, which satisfies

$$
H(U, p)=(1-p)\left[L(U)-L\left(U_{0}\right)\right]+p[A(U)-f(r)]=0, \quad p \in[0,1],
$$

or

$$
H(U, p)=L(U)-L\left(U_{0}\right)+p L\left(U_{0}\right)+p[N(U)-f(r)]=0 .
$$

In the above Eqs. (18) and (19), $p \in[0,1]$ is an embedding parameter, $u_{0}$ is an initial approximation of (15), which satisfies the boundary conditions.

Also, from (18) and (19), we will have

$$
H(U, 0)=L(U)-L\left(U_{0}\right)=0
$$

or

$$
H(U, 0)=A(U)-f(r)=0 .
$$

The changing process of $p$ from zero to unity is just that of $U(r, p)$ from $u_{0}(r)$ to $u(r)$. This is referred to homotopy in topology. Using the embedding parameter $p$ as a small parameter, the solution of Eqs. (18) and (19) can be assumed to be written as a power series in $p$ as given in Eq. (22)

$$
U=U_{0}+p U_{1}+p^{2} U_{2}+\ldots
$$

It should be pointed out that of all the values of $p$ between 0 and $1, p=1$ produces the best result. Therefore, setting $p=1$, results in the approximation solution of (14)

$$
u=\lim _{p \rightarrow 1} U=U_{0}+U_{1}+U_{2}+\ldots
$$

The basic idea expressed above is a combination of homotopy and perturbation method. Hence, the method is called homotopy perturbation method (HPM), which has eliminated the limitations of the traditional perturbation methods. On the other hand, this technique can have full advantages of the traditional perturbation techniques. The series (23) is convergent for most cases.

\subsection{Application of the homotopy perturbation method to the present problem}

According to homotopy perturbation method (HPM), one can construct a homotopy for Eqs. (9)-(11) as

$$
\begin{aligned}
H_{1}(p, \eta)= & (1-p)\left[\frac{\mathrm{d}^{4} f}{\partial \eta^{4}}-C\right]+ \\
& p\left[\frac{d^{4} f}{\partial \eta^{4}}-S\left(\eta \frac{\mathrm{d}^{3} f}{\mathrm{~d} \eta^{3}}+3 \frac{\mathrm{d}^{2} f}{d \eta^{2}}+f \frac{\mathrm{d} f}{\mathrm{~d} \eta}-2 \frac{\mathrm{d} f}{\mathrm{~d} \eta} \frac{\mathrm{d}^{3} f}{\mathrm{~d} \eta^{3}}\right)-M^{2} \frac{\mathrm{d}^{2} f}{\mathrm{~d} \eta^{2}}-C\right]=0 \\
H_{2}(p, \eta)= & (1-p)\left[\frac{\mathrm{d}^{2} \theta}{\mathrm{d} \eta^{2}}\right]+ \\
& p\left[\frac{\mathrm{d}^{2} \theta}{\mathrm{d} \eta^{2}}+\operatorname{Pr} S\left(2 f \frac{\mathrm{d} \theta}{\mathrm{d} \eta}-\eta \frac{\mathrm{d} \theta}{\mathrm{d} \eta}\right)+\operatorname{Pr} S\left(N b \frac{\mathrm{d} \theta}{\mathrm{d} \eta} \frac{\mathrm{d} \varphi}{\mathrm{d} \eta}+N t\left(\frac{\mathrm{d} \theta}{\mathrm{d} \eta}\right)^{2}\right)\right]=0 \\
H_{3}(p, \eta)= & (1-p)\left[\frac{\mathrm{d}^{2} \varphi}{\mathrm{d} \eta^{2}}\right]+p\left[\frac{\mathrm{d}^{2} \varphi}{\mathrm{d} \eta^{2}}+\operatorname{Le} S(2 f-\eta) \frac{\mathrm{d} \theta}{\mathrm{d} \eta}+\frac{N t}{N b} \frac{\mathrm{d}^{2} \varphi}{\mathrm{d} \eta^{2}}\right]=0 .
\end{aligned}
$$


Taking power series of velocity, temperature and concentration fields, gives

$$
\begin{aligned}
f & =f_{0}+p f_{1}+p^{2} f_{2}+\ldots \\
\theta & =\theta_{0}+p \theta_{1}+p^{2} \theta_{2}+\ldots \\
\varphi & =\varphi_{0}+p \varphi_{1}+p^{2} \varphi_{2}+\ldots
\end{aligned}
$$

The substitution of Eq. (27) into Eq. (24) yields

$$
\begin{array}{ll}
p^{0}: & \frac{\mathrm{d}^{4} f_{0}}{\mathrm{~d} \eta^{4}} \\
p^{1}: & \frac{\mathrm{d}^{4} f_{1}}{\mathrm{~d} \eta^{4}}-M^{2} \frac{\mathrm{d}^{2} f_{0}}{\mathrm{~d} \eta^{2}}-C-S\left(3 \frac{\mathrm{d}^{2} f_{0}}{\mathrm{~d} \eta^{2}}+\eta \frac{\mathrm{d}^{3} f_{0}}{\mathrm{~d} \eta^{3}}+f_{0} \frac{\mathrm{d} f_{0}}{\mathrm{~d} \eta}-2 \frac{\mathrm{d} f_{0}}{\mathrm{~d} \eta} \frac{\mathrm{d}^{3} f_{0}}{\mathrm{~d} \eta^{3}}\right), \\
p^{2}: & \frac{\mathrm{d}^{4} f_{2}}{\mathrm{~d} \eta^{4}}-M^{2} \frac{\mathrm{d}^{2} f_{1}}{\mathrm{~d} \eta^{2}}- \\
& S\left(3 \frac{\mathrm{d}^{2} f_{1}}{\mathrm{~d} \eta^{2}}+\frac{\mathrm{d}^{3} f_{1}}{\mathrm{~d} \eta^{3}}-\frac{\mathrm{d} f_{0}}{\mathrm{~d} \eta}\left(2 \frac{\mathrm{d} f_{1}}{\mathrm{~d} \eta}-f_{1}\right)-\frac{\mathrm{d} f_{1}}{\mathrm{~d} \eta}\left(2 \frac{\mathrm{d} f_{0}}{\mathrm{~d} \eta}-f_{0}+2\right)\right) \\
p^{3}: & \ldots
\end{array}
$$

The boundary conditions for Eqs. (30)-(32) are

$$
\begin{aligned}
f_{0}(0) & =A, \quad f_{1}(0)=0, \quad f_{2}(0)=0 \\
\frac{\mathrm{d} f_{0}(0)}{\mathrm{d} \eta} & =-\beta \frac{\mathrm{d}^{2} f_{0}(0)}{\mathrm{d} \eta^{2}}, \quad \frac{\mathrm{d} f_{1}(0)}{\mathrm{d} \eta}=-\beta \frac{\mathrm{d}^{2} f_{1}(0)}{\mathrm{d} \eta^{2}}, \quad \frac{\mathrm{d} f_{2}(0)}{\mathrm{d} \eta}=-\beta \frac{\mathrm{d}^{2} f_{2}(0)}{\mathrm{d} \eta^{2}}, \\
f_{0}(1) & =\frac{1}{2}, \quad f_{1}(1)=0, \quad f_{2}(1)=0 \\
\frac{\mathrm{d} f_{0}(1)}{\mathrm{d} \eta} & =\beta \frac{\mathrm{d}^{2} f_{0}(1)}{\mathrm{d} \eta^{2}}, \quad \frac{\mathrm{d} f_{1}(1)}{\mathrm{d} \eta}=\beta \frac{\mathrm{d}^{2} f_{1}(1)}{\mathrm{d} \eta^{2}}, \quad \frac{\mathrm{d} f_{2}(1)}{\mathrm{d} \eta}=\beta \frac{\mathrm{d}^{2} f_{2}(1)}{\mathrm{d} \eta^{2}} .
\end{aligned}
$$

The substitution of Eq. (28) into Eq. (25) yields

$$
\begin{aligned}
p^{0}: & \frac{\mathrm{d}^{2} \theta_{0}}{\mathrm{~d} \eta^{2}} \\
p^{1}: & \frac{\mathrm{d}^{2} \theta_{1}}{\mathrm{~d} \eta^{2}}-\operatorname{Pr} S\left(\eta \frac{\mathrm{d} \theta_{0}}{\mathrm{~d} \eta}-2 \frac{\mathrm{d} \theta_{0}}{\mathrm{~d} \eta} f_{0}\right)+\operatorname{Pr}\left(N b \frac{\mathrm{d} \theta_{0}}{\mathrm{~d} \eta} \frac{\mathrm{d} \varphi_{0}}{\mathrm{~d} \eta}+N t\left(\frac{\mathrm{d} \theta_{0}}{\mathrm{~d} \eta}\right)^{2}\right) \\
p^{2}: & \frac{\mathrm{d}^{2} \theta_{2}}{\mathrm{~d} \eta^{2}}+\operatorname{Pr} S\left(2 \frac{\mathrm{d} \theta_{0}}{\mathrm{~d} \eta} f_{1}-\frac{\mathrm{d} \theta_{1}}{\mathrm{~d} \eta}+2 \frac{\mathrm{d} \theta_{1}}{\mathrm{~d} \eta} f_{0}\right)+ \\
& \operatorname{Pr}\left(N b \frac{\mathrm{d} \theta_{1}}{\mathrm{~d} \eta} \frac{\mathrm{d} \varphi_{0}}{\mathrm{~d} \eta}+N b \frac{\mathrm{d} \theta_{0}}{\mathrm{~d} \eta} \frac{\mathrm{d} \varphi_{1}}{\mathrm{~d} \eta}+2 N t \frac{\mathrm{d} \theta_{0}}{\mathrm{~d} \eta} \frac{\mathrm{d} \theta_{1}}{\mathrm{~d} \eta}\right) \\
p^{3}: & \quad \ldots
\end{aligned}
$$

The boundary conditions for Eqs. (34)-(36) are

$$
\begin{aligned}
& \theta_{0}(0)=1-\gamma \frac{\mathrm{d} \theta_{0}}{\mathrm{~d} \eta}, \quad \theta_{1}(0)=-\gamma \frac{\mathrm{d} \theta_{1}}{\mathrm{~d} \eta}, \quad \theta_{2}(0)=-\gamma \frac{\mathrm{d} \theta_{2}}{\mathrm{~d} \eta}, \\
& \theta_{0}(1)=\gamma \frac{\mathrm{d} \theta_{0}}{\mathrm{~d} \eta}, \quad \theta_{1}(1)=\gamma \frac{\mathrm{d} \theta_{1}}{\mathrm{~d} \eta}, \quad \theta_{2}(1)=\gamma \frac{\mathrm{d} \theta_{2}}{\mathrm{~d} \eta} .
\end{aligned}
$$


The substitution of Eq. (29) into Eq. (26) yields

$$
\begin{array}{ll}
p^{0}: & \frac{\mathrm{d}^{2} \varphi_{0}}{\mathrm{~d} \eta^{2}}+\left(\frac{N t}{N b} \frac{\mathrm{d}^{2} \theta_{0}}{\mathrm{~d} \eta^{2}}\right), \\
p^{1}: & \frac{\mathrm{d}^{2} \varphi_{1}}{\mathrm{~d} \eta^{2}}+\left(\frac{N t}{N b} \frac{\mathrm{d}^{2} \varphi_{1}}{\mathrm{~d} \eta^{2}}\right)-\operatorname{Le} S\left(\eta \frac{\mathrm{d} \theta_{0}}{\mathrm{~d} \eta}-2 \frac{\mathrm{d} \theta_{0}}{\mathrm{~d} \eta} f_{0}\right), \\
p^{2}: & \frac{\mathrm{d}^{2} \varphi_{2}}{\mathrm{~d} \eta^{2}}+\operatorname{Le} S\left(2 \frac{\mathrm{d} \theta_{0}}{\mathrm{~d} \eta} f_{1}-\eta \frac{\mathrm{d} \theta_{1}}{\mathrm{~d} \eta}+2 \frac{\mathrm{d} \theta_{1}}{\mathrm{~d} \eta} f_{0}\right)+\left(\frac{N t}{N b} \frac{\mathrm{d}^{2} \theta_{2}}{\mathrm{~d} \eta^{2}}\right), \\
p^{3}: & \cdots
\end{array}
$$

The boundary conditions for Eqs. (38)-(40) are

$$
\begin{array}{lll}
\varphi_{0}(0)=0, & \varphi_{1}(0)=0, & \varphi_{2}(0)=0, \\
\varphi_{0}(1)=0, & \varphi_{1}(1)=0, & \varphi_{2}(1)=0 .
\end{array}
$$

Solving Eq. (30) and applying the boundary condition (33) leads to

$$
f_{0}=A-\frac{(2 A-1) \eta^{3}}{(6 \beta-1)}+\frac{3(2 A-1) \eta^{2}}{(12 \beta-2)}-\frac{3 \beta(2 A-1) \eta}{(6 \beta-1)} .
$$

Also, on solving Eq. (34) and applying the boundary condition (37) yields

$$
\theta_{0}=\frac{\eta}{(2 \gamma-1)}+\frac{\gamma-1}{2 \gamma-1}
$$

And the solution of Eq. (38) with the application of the boundary condition (41) is

$$
\varphi_{0}=0 .
$$

On solving Eq. (31) and applying the boundary condition (33), one arrives at

$$
\begin{aligned}
f_{1}= & \eta^{4}\left(\frac{C}{24}-\frac{S}{16}-\frac{A^{2} S}{8}+\frac{3 A S}{16}-\frac{S(2 A-1)^{2}}{48(6 \beta-1)^{2}}+\frac{(2 A-1)\left(12 M^{2}+20 S-10 A S\right)}{96(6 \beta-1)}\right)+ \\
& \frac{C^{19} \eta^{2}}{2}+\frac{C^{20} \eta^{3}}{6}-\eta\left(\frac{C}{24}+\frac{C}{12}+\frac{C^{20}}{6}-\frac{29 S}{480}\right)-\frac{7 A^{2} S}{60}+\frac{43 A S}{240}-\frac{53 S(2 A-1)^{2}}{10080(6 \beta-1)^{2}}- \\
& \frac{16 S(2 A-1)^{2}}{3360(6 \beta-1)}+\frac{S(57-78 A)(2 A-1)}{1440(6 \beta-1)^{2}}+\frac{(2 A-1)\left(12 M^{2}+20 S-10 A S\right)}{96(6 \beta-1)}- \\
& \frac{(2 A-1)\left(24 M^{2}+122 S-64 A S\right)}{480(6 \beta-1)}-\frac{S(57-78 A)(2 A-1)}{1440(6 \beta-1)}-\frac{\eta^{6}\left(7 S(2 A-1)^{2}\right)}{96(6 \beta-1)^{2}}+ \\
& \frac{\eta^{7}\left(17 S(2 A-1)^{2}\right)}{336(6 \beta-1)^{2}}-\frac{\eta^{8}\left(17 S(2 A-1)^{2}\right)}{1120(6 \beta-1)^{2}}+\frac{\eta^{9}\left(S(2 A-1)^{2}\right)}{1008(6 \beta-1)^{2}}+ \\
& \eta^{5}\left(\frac{S}{480}+\frac{A^{2} S}{120}-\frac{A S}{120}+\frac{5 S(2 A-1)^{2}}{96(6 \beta-1)^{2}}-\frac{(2 A-1)\left(24 M^{2}+122 S-64 A S\right)}{480(6 \beta-1)}\right)
\end{aligned}
$$

Also, on solving Eq. (35) and applying the boundary condition (37) gives

$$
\begin{aligned}
\theta_{1}= & \frac{\operatorname{Pr} S}{106}\left(\frac{2 A-1}{(\beta-1)(2 \gamma-1)}\right) \eta^{5}-\frac{\operatorname{Pr} S}{4}\left(\frac{2 A-1}{(6 \beta-1)(2 \gamma-1)}\right) \eta^{4}+ \\
& \frac{\operatorname{Pr} S}{6}\left(\frac{1-2 \gamma-2 A+4 A \gamma}{(2 \gamma-1)^{2}}\right)+\frac{\operatorname{Pr} S}{6}\left(\frac{2 A-1}{(6 \beta-1)(2 \gamma-1)}\right) \eta^{3}- \\
& \frac{\operatorname{Pr} S}{60}\left(\frac{2 A-1}{(6 \beta-1)(2 \gamma-1)}\right) \eta-\frac{\operatorname{Pr} N t}{2(2 \gamma-1)^{2}}-\frac{\operatorname{Pr} S}{6} \frac{(1-2 \gamma-2 A+4 A \gamma)}{2(2 \gamma-1)^{2}} .
\end{aligned}
$$


It can easily be shown that the solution of Eq. (39) after the application of the boundary condition (41) yields

$$
\begin{aligned}
\varphi_{1}= & \frac{\operatorname{Pr} S N b}{N t}\left\{\frac{\gamma(1-2 A)}{5(6 \beta-1)(2 \gamma-1)^{2}}-\frac{(1-2 A) \eta^{5}}{10(6 \beta-1)(2 \gamma-1)^{2}}+\frac{(1-2 A)}{4(6 \beta-1)(2 \gamma-1)^{2}}-\right. \\
& \frac{\gamma(1-2 A) \eta^{4}}{2(6 \beta-1)(2 \gamma-1)^{2}}-\frac{\beta(1-2 A) \eta^{3}}{(6 \beta-1)(2 \gamma-1)^{2}}+\frac{(1-6 \beta)(1-2 A)}{(6 \beta-1)(2 \gamma-1)^{2}}- \\
& \frac{(1-2 A-6 \beta+12 A \beta) \eta^{2}}{2(6 \beta-1)(2 \gamma-1)^{2}}-\frac{N t(1-6 \beta) \eta^{2}}{2 S(6 \beta-1)(2 \gamma-1)^{2}}+\frac{\beta(1-2 A)}{(6 \beta-1)(2 \gamma-1)^{2}}+ \\
& \frac{(1-2 A-6 \beta+12 A \beta)}{2(6 \beta-1)(2 \gamma-1)^{2}}+\frac{N t(1-6 \beta)}{2 S(6 \beta-1)(2 \gamma-1)^{2}}-\frac{\gamma(1-6 \beta)(1-2 A)}{(6 \beta-1)(2 \gamma-1)^{2}}- \\
& \left.\frac{\gamma(1-2 A \beta)}{5(6 \beta-1)(2 \gamma-1)^{2}}+\frac{\gamma(1-2 A \beta) \eta}{2(6 \beta-1)(2 \gamma-1)^{2}}\right\} .
\end{aligned}
$$

In the same way, $f_{2}(\eta), \theta_{2}(\eta)$ and $\varphi_{2}(\eta)$ in Eqs. (32), (36) and (40) are solved using the boundary conditions (33), (37) and (41), respectively. Although, the resulting solutions and the other subsequent solutions are too long to be shown in this paper, they are included in the simulated results shown graphically in the results and discussion section.

The substitution of Eqs. (42) and (45) into the power series (27) yields

$$
\begin{aligned}
f(\eta)= & A-\frac{(2 A-1) \eta^{3}}{(6 \beta-1)}+\frac{3(2 A-1) \eta^{2}}{(12 \beta-2)}-\frac{3 \beta(2 A-1) \eta}{(6 \beta-1)}+ \\
& \eta^{4}\left(\frac{C}{24}-\frac{S}{16}-\frac{A^{2} S}{8}+\frac{3 A S}{16}-\frac{S(2 A-1)^{2}}{48(6 \beta-1)^{2}}+\frac{(2 A-1)\left(12 M^{2}+20 S-10 A S\right)}{96(6 \beta-1)}\right)+ \\
& \frac{C^{19} \eta^{2}}{2}+\frac{C^{20} \eta^{3}}{6}-\eta\left(\frac{C}{24}+\frac{C}{12}+\frac{C^{20}}{6}-\frac{29 S}{480}\right)-\frac{7 A^{2} S}{60}+\frac{43 A S}{240}- \\
& \frac{53 S(2 A-1)^{2}}{10080(6 \beta-1)^{2}}-\frac{16 S(2 A-1)^{2}}{3360(6 \beta-1)}+\frac{S(57-78 A)(2 A-1)}{1440(6 \beta-1)^{2}}+ \\
& \frac{(2 A-1)\left(12 M^{2}+20 S-10 A S\right)}{96(6 \beta-1)}-\frac{(2 A-1)\left(24 M^{2}+122 S-64 A S\right)}{480(6 \beta-1)}- \\
& \frac{S(57-78 A)(2 A-1)}{1440(6 \beta-1)}-\frac{\eta^{6}\left(7 S(2 A-1)^{2}\right)}{96(6 \beta-1)^{2}}+\frac{\eta^{7}\left(17 S(2 A-1)^{2}\right)}{336(6 \beta-1)^{2}}- \\
& \frac{\eta^{8}\left(17 S(2 A-1)^{2}\right)}{1120(6 \beta-1)^{2}}+\frac{\eta^{9}\left(S(2 A-1)^{2}\right)}{1008(6 \beta-1)^{2}}+ \\
& \eta^{5}\left(\frac{S}{480}+\frac{A^{2} S}{120}-\frac{A S}{120}+\frac{5 S(2 A-1)^{2}}{96(6 \beta-1)^{2}}-\frac{(2 A-1)\left(24 M^{2}+122 S-64 A S\right)}{480(6 \beta-1)}\right) .(48)
\end{aligned}
$$

Also, substituting Eqs. (43) and (46) into the power series (28) gives

$$
\begin{aligned}
\theta(\eta)= & \frac{\eta}{(2 \gamma-1)}+\frac{\gamma-1}{2 \gamma-1}+\frac{\operatorname{Pr} S}{106}\left(\frac{2 A-1}{(\beta-1)(2 \gamma-1)}\right) \eta^{5}-\frac{\operatorname{Pr} S}{4}\left(\frac{2 A-1}{(6 \beta-1)(2 \gamma-1)}\right) \eta^{4}+ \\
& \frac{\operatorname{Pr} S}{6}\left(\frac{1-2 \gamma-2 A+4 A \gamma}{(2 \gamma-1)^{2}}\right)+\frac{\operatorname{Pr} S}{6}\left(\frac{2 A-1}{(6 \beta-1)(2 \gamma-1)}\right) \eta^{3}- \\
& \frac{\operatorname{Pr} S}{60}\left(\frac{2 A-1}{(6 \beta-1)(2 \gamma-1)}\right) \eta-\frac{\operatorname{Pr} N t}{2(2 \gamma-1)^{2}}-\frac{\operatorname{Pr} S}{6} \frac{(1-2 \gamma-2 A+4 A \gamma)}{2(2 \gamma-1)^{2}}+\ldots \text { (49) }
\end{aligned}
$$


Similarly, substituting Eqs. (44) and (47) into the power series (29) yields

$$
\begin{aligned}
\varphi(\eta)= & \frac{\operatorname{Pr} S N b}{N t}\left\{\frac{\gamma(1-2 A)}{5(6 \beta-1)(2 \gamma-1)^{2}}-\frac{(1-2 A) \eta^{5}}{10(6 \beta-1)(2 \gamma-1)^{2}}+\frac{(1-2 A)}{4(6 \beta-1)(2 \gamma-1)^{2}}-\right. \\
& \frac{\gamma(1-2 A) \eta^{4}}{2(6 \beta-1)(2 \gamma-1)^{2}}-\frac{\beta(1-2 A) \eta^{3}}{(6 \beta-1)(2 \gamma-1)^{2}}+\frac{(1-6 \beta)(1-2 A)}{(6 \beta-1)(2 \gamma-1)^{2}}- \\
& \frac{(1-2 A-6 \beta+12 A \beta) \eta^{2}}{2(6 \beta-1)(2 \gamma-1)^{2}}-\frac{N t(1-6 \beta) \eta^{2}}{2 S(6 \beta-1)(2 \gamma-1)^{2}}+\frac{\beta(1-2 A)}{(6 \beta-1)(2 \gamma-1)^{2}}+ \\
& \frac{(1-2 A-6 \beta+12 A \beta)}{2(6 \beta-1)(2 \gamma-1)^{2}}+\frac{N t(1-6 \beta)}{2 S(6 \beta-1)(2 \gamma-1)^{2}}-\frac{\gamma(1-6 \beta)(1-2 A)}{(6 \beta-1)(2 \gamma-1)^{2}}- \\
& \left.\frac{\gamma(1-2 A \beta)}{5(6 \beta-1)(2 \gamma-1)^{2}}+\frac{\gamma(1-2 A \beta) \eta}{2(6 \beta-1)(2 \gamma-1)^{2}}\right\}
\end{aligned}
$$

\section{Results and discussion}

Table 1 shows the comparison of the results of the numerical method (NM) and the homotopy perturbation method used in this work. From the results, it could be inferred that the results of the presents work agrees with the results of the numerical method using shooting method with the sixth-order Runge-Kutta method.

Table 1. Comparison of values of temperature jump parameter $(\gamma)$ when $A=2, S=1, N t=N b=0.2$, $\beta=0.05, M=0.5, L e=\operatorname{Pr}=1.0, C=0$

\begin{tabular}{|c|c|c|}
\hline \multirow{2}{*}{$\gamma$} & \multicolumn{2}{|c|}{ Dimensionless temperature } \\
\cline { 2 - 3 } & $\mathrm{NM}$ & Present work \\
\hline 0.00 & 1.0000 & 1.0000 \\
\hline 0.10 & 1.2231 & 1.2232 \\
\hline 0.15 & 1.4053 & 1.4053 \\
\hline 0.20 & 1.6214 & 1.6215 \\
\hline 0.25 & 1.7312 & 1.7311 \\
\hline 0.30 & 1.8656 & 1.8656 \\
\hline 0.35 & 2.2013 & 2.2011 \\
\hline 0.40 & 3.1052 & 3.1052 \\
\hline
\end{tabular}

In order to further establish the accuracy of the solution of HPM, the results of the present study (in the absence of slip parameter) are further compared with the results of the numerical method using shooting method with six-order Runge-Kutta method. The values of local Nusselt number, $N u_{L}$ and local Sherwood number, $S h_{L}$ have been calculated for various values of $N b$ and $N t$. An excellent agreement is found between the two set of results as shown in Table 2. Therefore, the use of the homotopy perturbation method for the analysis of the double diffusive models is justified.

The obtained analytical solutions are reported graphically to show the influence of various fluid parameters. The effect of slip parameter is illustrated in Fig. 2 where it is shown that radial velocity component increases with an increase in slip parameter near the lower disk i.e. $\eta>0$ and $\eta<0.5$ (not accurately determined) and reverse is the case as it approaches the upper disk, i.e., $\eta>0.5$ and $\eta<1$ (not accurately determined) which can be physically explained due to increase in slip components leads to a corresponding decrease in shear stress. 
Table 2. Comparison of the values of the local Nusselt and local Sheerwood number for various values of $N b$ and $N t$ with $\beta=\gamma=0$

\begin{tabular}{|c|c|c|c|c|c|}
\hline$N b$ & $N t$ & \multicolumn{2}{|c|}{$N u_{L}=-\theta^{\prime}(1)$} & \multicolumn{2}{c|}{$S h_{L}=-\varphi^{\prime}(1)$} \\
\hline & & $\mathrm{NM}$ & $\mathrm{HPM}$ & $\mathrm{NM}$ & $\mathrm{HPM}$ \\
\hline 0.1 & 0.1 & 0.5263 & 0.5263 & 0.8660 & 0.8660 \\
\hline 0.5 & & 0.6343 & 0.6343 & 0.5301 & 0.5300 \\
\hline 1.0 & & 0.7864 & 0.7864 & 0.4860 & 0.4860 \\
\hline 1.5 & & 0.9557 & 0.9556 & 0.4699 & 0.4698 \\
\hline 1.5 & 0.5 & 1.1768 & 1.1768 & 0.4018 & 0.4018 \\
\hline & 1.0 & 1.4858 & 1.4857 & 0.1262 & 0.1261 \\
\hline & 1.5 & 1.8231 & 1.8230 & 0.3908 & 0.3908 \\
\hline & 2.0 & 2.1792 & 2.1792 & 1.1680 & 1.1678 \\
\hline
\end{tabular}

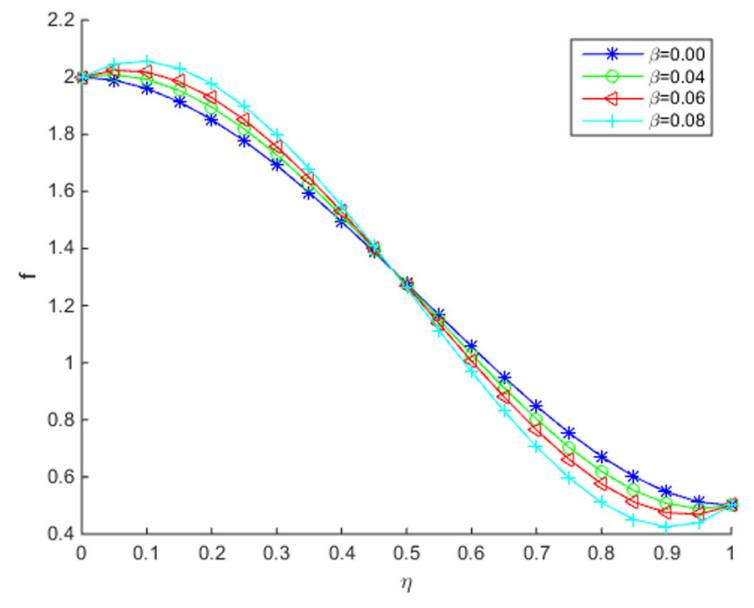

Fig. 2. Effect of slip parameter on velocity profile for $A=2, S=1, N t=N b=0.2, \gamma=0.1$, $M=0.5, L e=\operatorname{Pr}=1.0, C=-1$

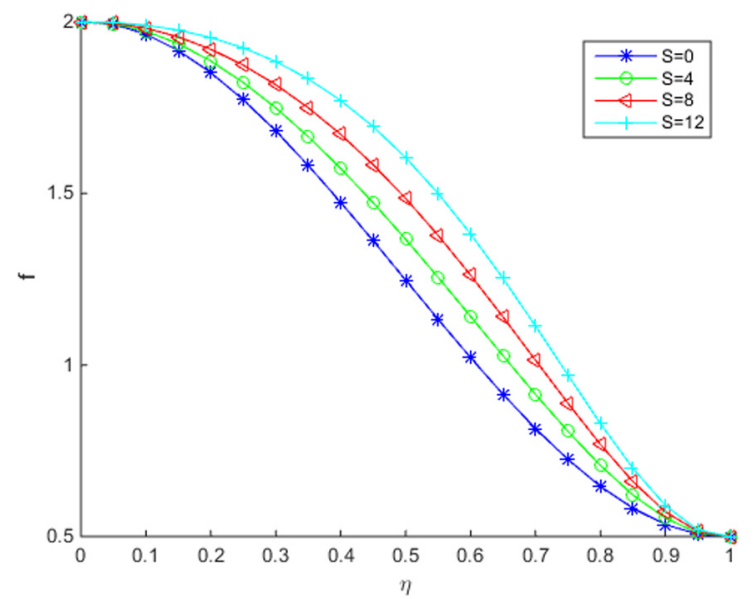

Fig. 4. Effect of squeezing parameter on velocity profile for $A=2, \beta=0.05, N t=N b=0.2$, $\gamma=0.1, M=0.5, L e=\operatorname{Pr}=1.0, C=-1$

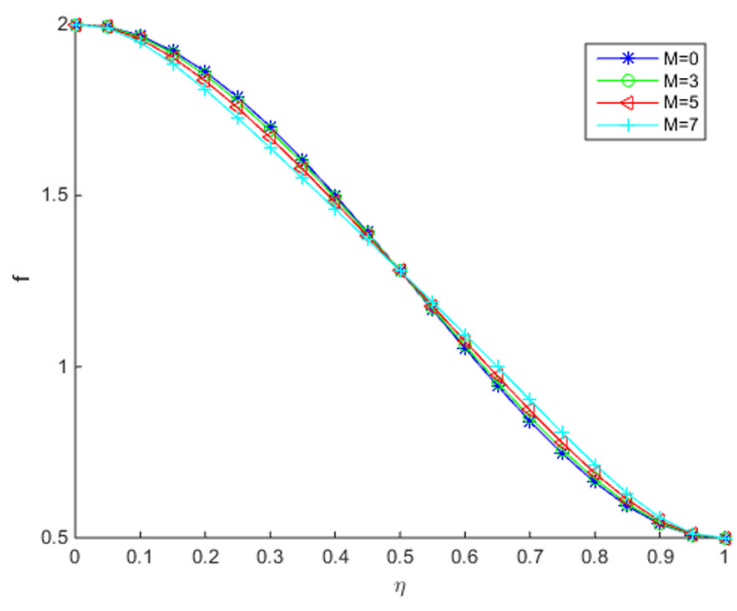

Fig. 3. Effect of Hartmann parameter on velocity profile for $A=2, S=1, N t=N b=0.2$, $\gamma=0.1, \beta=0.05, L e=\operatorname{Pr}=1.0, C=-1$

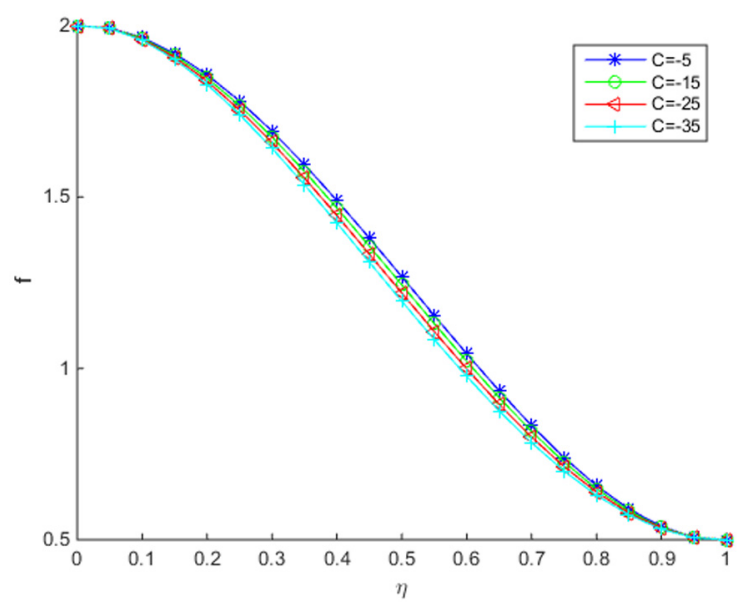

Fig. 5. Effect of pressure gradient on velocity profile for $A=2, S=1, N t=N b=0.2, \gamma=0.1$, $M=0.5, L e=\operatorname{Pr}=1.0, \beta=0.05$ 
A reverse trend is observed clearly from Fig. 3 which shows the effect of increasing Hartmannparameter $(M)$, it is shown that at increasing values of $M$ the velocity decreases slightly near the lower disk and as the upper disk is approached the velocity increases slightly due to the increase in boundary layer thickness caused by the Lorentz or magnetic force field. As squeeze parameter $(S)$ increases which is demonstrated in Fig. 4 the radial velocity component increases, though effect is maximum at the lower disk and minimum at the upper disk. Fig. 5 depicts the effect of increasing pressure term $(C)$ on the fluid flow; it is shown here that with increasing $C$ a very slight increase in velocity component is observed.

Temperature jump effect $(\gamma)$ on temperature profile is shown in Fig. 6, where it is depeicted that as $\gamma$ increases temperature distribution increases towards the lower disk where it decreases towards the upper disk. In the absence of slip i.e. $\gamma=0$ it is observed that temperature distribution equals one at the lower plate and zero at the upper plate. Influence of thermophoresis parameter $(N t)$ is demonstrated in Fig. 7 which depicts that increasing values of $N t$, the temperature distribution is maximum at the lower disk, only to fall rapidly towards the upper disk. The effect of squeeze parameter $(S)$ on temperature distribution is seen in Fig. 8 which illustrates at

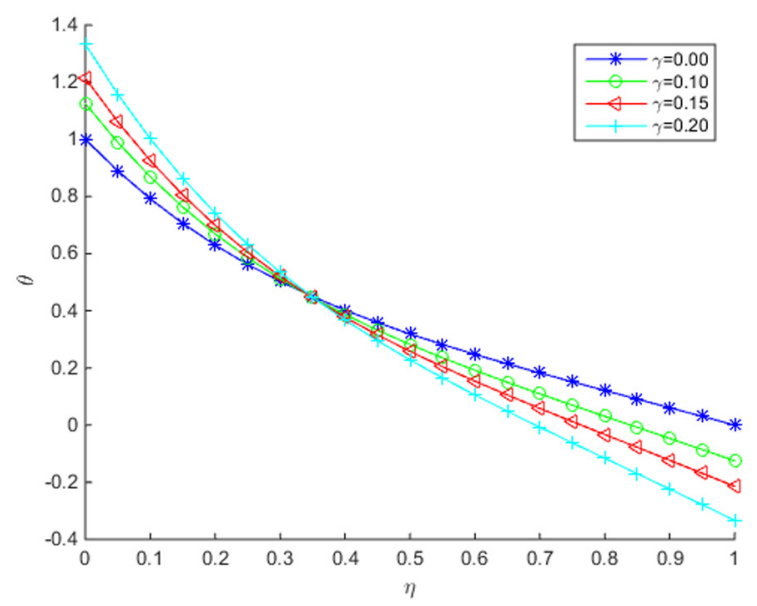

Fig. 6. Effect of jump parameter on temperature profile for $A=2, S=14, N t=N b=0.2$, $\beta=0.05, M=0.5, L e=\operatorname{Pr}=1.0, C=-1$

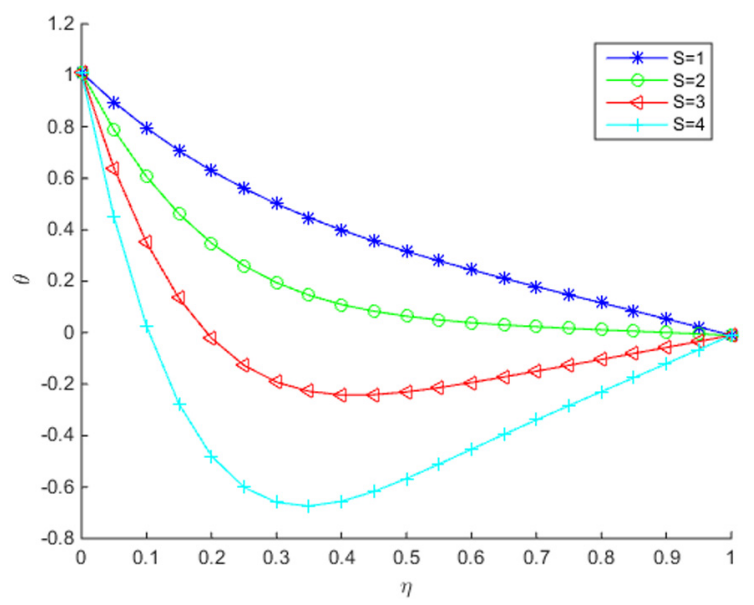

Fig. 8. Effect of squeeze parameter on temperature profile for $A=2, \gamma=0.1, N t=N b=0.2$, $\beta=0.05, M=0.5, L e=\operatorname{Pr}=1.0, C=-1$

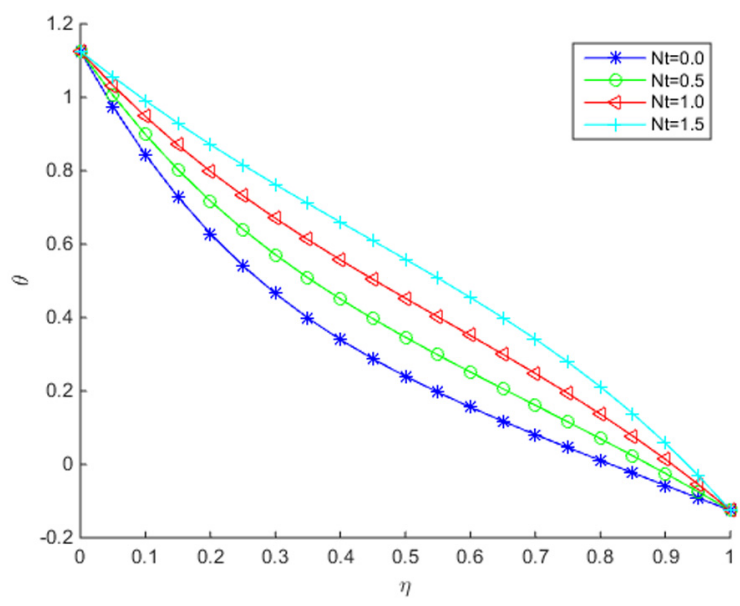

Fig. 7. Effect of thermophoresis parameter on temperature profile for $A=2, S=1, \gamma=0.1$, $N b=0.2, \beta=0.05, M=0.5, L e=\operatorname{Pr}=1.0$, $C=-1$

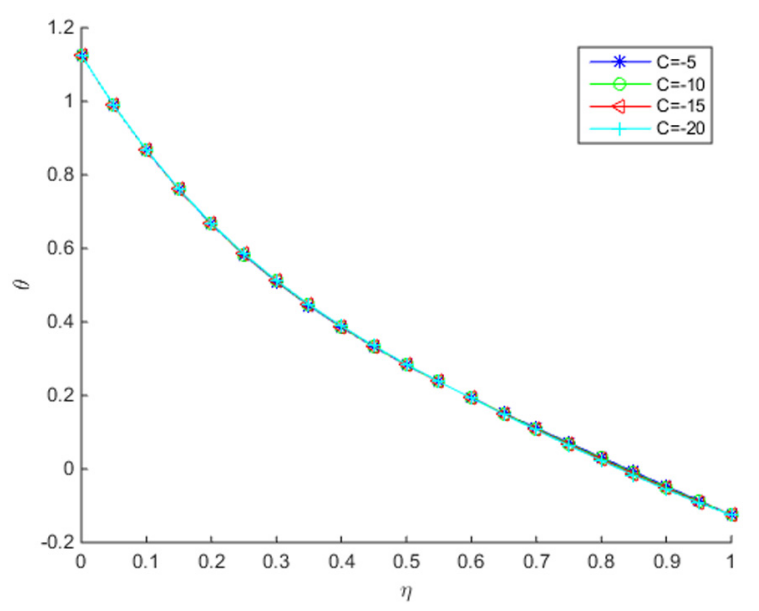

Fig. 9. Effect of pressure gradient on temperature profile for $A=2, S=1, N t=N b=0.2$, $\beta=0.05, M=0.5, L e=\operatorname{Pr}=1.0, \gamma=0.1$ 
increasing values $S$ temperature at the lower disk reduces while temperature at the upper disk increases which can be physically explained as increase in $S$ leads to a corresponding decrease in kinematic viscosity and vice versa. It is obvious from Fig. 9 that increasing pressure term $(C)$ as no significant effect on temperature distribution.

Influence of Lewis number $(L e)$ is observed in Fig. 10 where it is depicted that increasing $L e$ evokes a corresponding increase in concentration distribution at the region closer to the lower disk, though decreases rapidly as it moves towards the upper plate. Thermophoresis parameter $(N t)$ effect is observed in Fig. 11, at increasing values of $N t$ the concentration profile increases significantly but towards the upper plate there is a steady reduction. Fig. 12 depicts the effect of Brownian motion parameter $(\mathrm{Nb})$ as observed at increasing value of $\mathrm{Nb}$ concentration profile decreases significantly, which falls rapidly as it approaches the upper disk at suction. Also when squeeze parameter $(S)$ is increased, the effect is illustrated in Fig. 13 where the concentration distribution increases significantly near the wall close to the lower disk but falls rapidly as the upper disk is approached during suction.

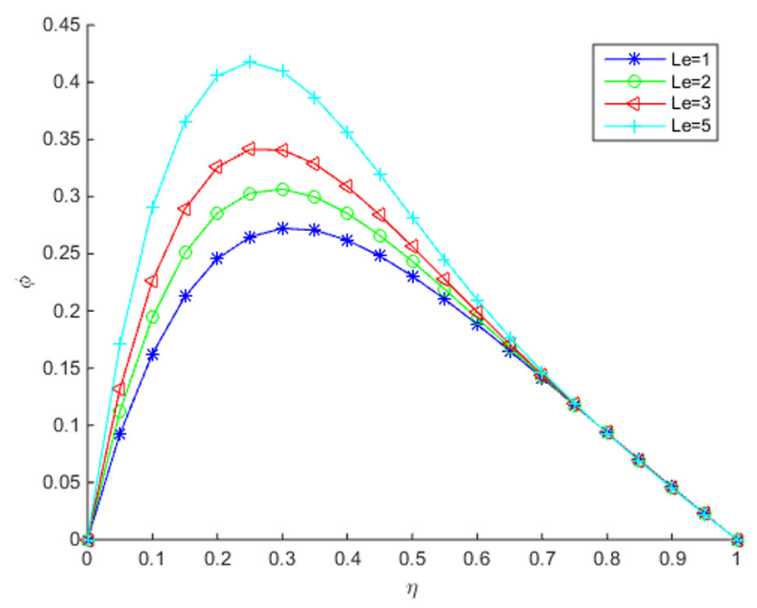

Fig. 10. Effect of Lewis number on concentration profile for $A=2, S=1, N t=N b=0.2$, $\beta=0.05, M=0.5, \gamma=0.1, \operatorname{Pr}=1.0, C=-1$

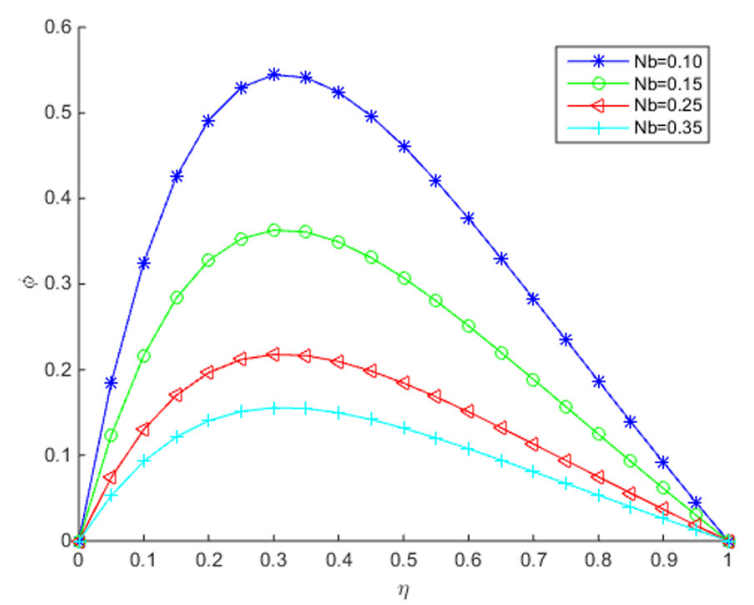

Fig. 12. Effect of Brownian motion parameter on concentration profile for $A=2, S=1, N t=0.2$, $\gamma=0.1, \beta=0.05, M=0.5, L e=\operatorname{Pr}=1.0$, $C=-1$

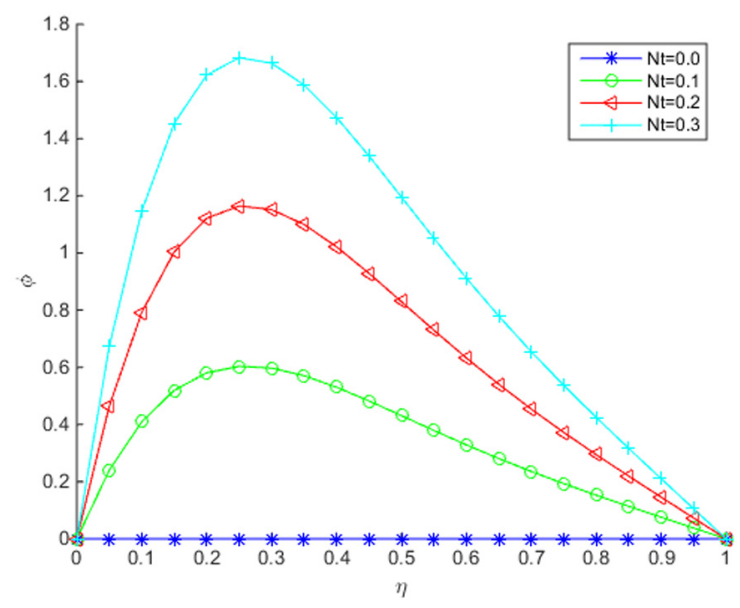

Fig. 11. Effect of thermophoresis parameter on concentration profile for $A=2, S=1, \gamma=0.1$, $N b=0.2, \beta=0.05, M=0.5, L e=\operatorname{Pr}=1.0$, $C=-1$

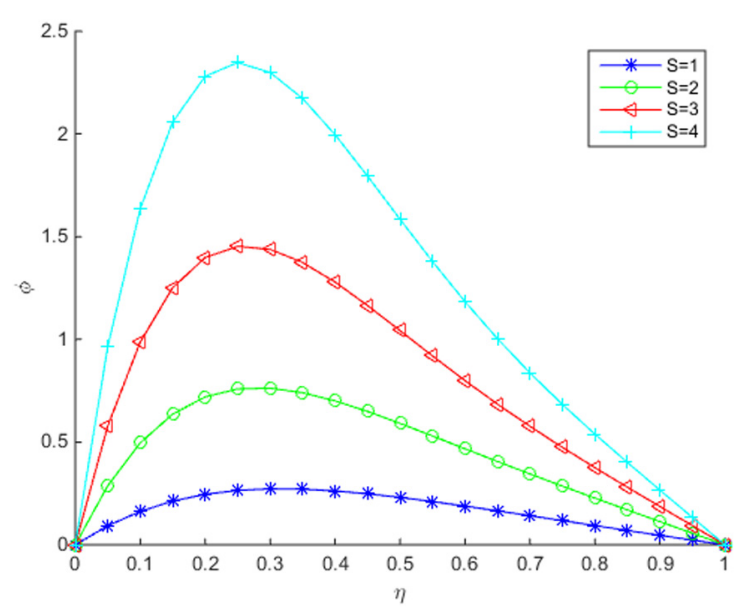

Fig. 13. Effect of squeeze parameter on concentration profile for $A=2, N b=N t=0.2, \gamma=0.1$, $\beta=0.05, M=0.5, L e=\operatorname{Pr}=1.0, C=-1$ 


\section{Conclusion}

In this study, the flow, heat transfer and concentration characteristics of an electrically conducting nanofluid under magnetohydrodynamics with pressure gradient under the influences of slip and temperature-jump conditions have been analyzed using the homotopy perturbation method. Analytical solutions were reported graphically to demonstrate the influence of various flow parameters on the flow phenomena. Effects of parameters such as thermophoresis, Brownian motion, Lewis number and pressure gradient on flow and heat transfer was investigated. This study is significantly important in the in energy conservation, friction reduction and micro mixing biological samples.

\section{References}

[1] Ariel, P. D., Axisymmetric flow due to stretching sheet with partial slip, Computer and Mathematics with Application 333 (2007) 381-400. https://doi.org/10.1016/j.camwa.2006.12.063

[2] Choi, C.H., Westin, J. A., Breur, K. S., To slip or not slip water flows in hydrophilic and hydrophobic microchannels, Proceedings of IMECE 2002, New Orleans, USA, Article ID: 33707, 2002. https://doi.org/10.1115/IMECE2002-33707

[3] Das, K., Impact of thermal radiation on MHD slip flow over a flat plate withvariable fluid properties, Heat and Mass Transfer 48 (2012) 767-778. https://doi.org/10.1007/s00231-011-0924-3

[4] Das, K., Slip effects on heat and mass transfer in MHD micro polar fluid flow over an inclined plate with thermal radiation and chemical reaction, International Journal of Numerical Methods in Fluids 70 (2016) 96-101. https://doi.org/10.1002/fld.2683

[5] Das, K., Slip flow and convective heat transfer of nanofluid over a permeable stretching surface, Computers and Physics 64(1) (2012) 34-42. https://doi.org/10.1016/j.compfluid.2012.04.026

[6] Das, K., Jana, S., Acharya, N., Slip effects on squeezing flow of nanofluid between two parallel disks, International Journal of Applied Mechanics and Engineering 21(1) (2016) 5-20. https://doi.org/10.1515/ijame-2016-0001

[7] Domairry, G., Aziz, A., Approximate analysis of MHD squeeze flow between two parallel disks with suction or injection by homotopy perturbation method, Mathematical Problems in Engineering 2009 (2009) 1-19. https://doi.org/10.1155/2009/603916

[8] Ellahi, R., Hayat, T., Mahomed, F.M., Asghar, S., Effects of slip on nonlinear flows of a third grade fluid, NonlinearAnalysis: Real world Applications 11 (2010) 139-146. https://doi.org/10.1016/j.nonrwa.2008.10.051

[9] Fernandez, F. M., On some approximate methods for nonlinear models, Applied Mathematics and Computation 215 (1) (2009) 168-174. https://doi.org/10.1016/j.amc.2009.04.060

[10] Hashimi, M. R., Hayat, T., Alsaedi, A., On the analytic solutions for squeezing flow of nanofluids between parallel disks, Nonlinear Analysis Modeling and Control 17(4) (2014) 418-430.

[11] Hayat, T., Yousaf, A., Mustafa, M., Obadiat, S., MHD squeezing flow of second grade fluid between two parallel disk, International Journal of Numerical Fluids 69 (2011) 399-410. https://doi.org/10.1002/fld.2565

[12] He, J.H., A coupling method of homotopy technique and perturbation technique for nonlinear problems, International Journal of Non-Linear Mechanics 35 (2000) 37-43. https://doi.org/10.1016/S0020-7462(98)00085-7

[13] He, J. H., Homotopy perturbation technique, Computer Methods in Applied Mechanics and Engineering 178 (1999) 257-262. https://doi.org/10.1016/S0045-7825(99)00018-3

[14] He, J. H., New interpretation of homotopy perturbation method, International Journal of Modern Physics B 20 (2006) 2561-2568. https://doi.org/10.1142/S0217979206034819 
[15] He, J. H., New perturbation technique which is also valid for large parameters, Journal of Sound and Vibration 229 (2000) 1257-1263. https://doi.org/10.1006/jsvi.1999.2509

[16] He, J.H., Some asymptotic methods for strongly nonlinear equations, International Journal of Modern Physics B 20 (2006) 1141-1199. https://doi.org/10.1142/S0217979206033796

[17] Hussain, A., Mohyud-Cheema, S. T., Din, T. A., Analytical and numerical approaches to squeezing flow and heat transfer between two parallel disks with velocity slip and temperature jump, China Physics Letter 29 (2012) 1-5. https://doi.org/10.1088/0256-307X/29/11/114705

[18] Kandasamy, R., Loganathanb, P., Arasub, P. P., Scaling group transformationfor MHD boundary layer flow of a nanofluid past vertical stretching surface in the presence of suction/injection, Nuclear Engineering and Design 241 (2011) 2053-2059. https://doi.org/10.1016/j.nucengdes.2011.04.011

[19] Khan, W.A., Aziz, A., Double diffusive natural convection boundary layer flow in a porous medium saturated with a nanofluid over a vertical plate, prescribed surface heat, solute and nanofluid fluxes, International Journal of Thermal Sciences 50 (2011) 2154-2160. https://doi.org/10.1016/j.ijthermalsci.2011.05.022

[20] Khan, W.A., Aziz, A., Natural convective boundary layer flow over a vertical plate with uniform surface heat flux, International Journal of Thermal Sciences 50 (2011) 1207-1217. https://doi.org/10.1016/j.ijthermalsci.2011.02.015

[21] Kuznetsov, A. J., Nield, N. D., Natural convective boundary layer flow of a nanofluid past a vertical plate, International Journal of Thermal Sciences 49 (2010) 243-247. https://doi.org/10.1016/j.ijthermalsci.2009.07.015

[22] Makinde, D., Aziz, A., Boundary layer flow of a nanofluid past a stretching sheet with convective boundary conditions, International Journal of Thermal sciences 50 (2011) 1326-1332. https://doi.org/10.1016/j.ijthermalsci.2011.02.019

[23] Martin, M. J., Boyd, L. D., Momentum and heat transfer in a laminar boundary layer with slip flow, Journal of Thermophysics and Heat Transfer 20(4) (2006) 710-719. https://doi.org/10.2514/1.22968

[24] Matthew, M.T., Boyd, I. D., Nano boundary layer equation with nonlinear Navier boundary condition, Journal of Mathematical Analysis and Application 333 (2007) 381-400. https://doi.org/10.1016/j.jmaa.2006.08.047

[25] Mustafa, M., Hayat, T., Obadiat, S., On heat and mass transfer in the unsteady squeezing flow between parallel plates, Mechanica 47 (2012) 1581-1589.

https://doi.org/10.1007/s11012-012-9536-3

[26] Navier, C. L. M. H., On the laws of movement of fluids, Memoirs Academic Royal Science Institute France 6 (1823) 389-440. (in French)

[27] Ogunmola, B. Y., Akinshilo, A. T., Sobamowo, M. G., Perturbation solutions for the Hagen poiseuille flow and heat transfer of third grade fluid with temperature dependent viscosities and internal heat generation, International Journal of Engineering Mathematics 2016 (2016) 1-12. https://doi.org/10.1155/2016/8915745

[28] Rashidi, A. M., Shahmohamadi, H., Dinarvand, S., Analytic approximate solutions for unsteady two dimensional and axisymmetric squeezing flows between parallel plates, Mathematical Problems in Engineering 2008 (2008) 1-12. https://doi.org/10.1155/2008/935095

[29] Sheikholeslami, M., Influence of Coulomb forces on $\mathrm{Fe}_{3} \mathrm{O}_{4}-\mathrm{H}_{2} \mathrm{O}$ nanofluid thermal improvement, International Journal of Hydrogen Energy 42 (2) (2017) 821-829. https://doi.org/10.1016/j.jijydene.2016.09.185

[30] Sheikholeslami, M., Bhatti, M. M., Forced convection of nanofluid in presence of constant magnetic field considering shape effects of nanoparticles, International Journal of Heat and Mass Transfer 111 (2017) 1039-1049. https://doi.org/10.1016/j.ijheatmasstransfer.2017.04.070

[31] Sheikholeslami, M., Ganji, D. D., Heat transfer of Cu-water nanofluid flow between parallel plates, Powder Technology 235 (2013) 873-879. https://doi.org/10.1016/j.powtec.2012.11.030 
[32] Sheikholeslami, M., Ganji, D. D., Nanofluid flow and heat transfer between parallel plates considering Brownian motion using DTM, Computer Methods in Applied Mechanics and Engineering 283(1) (2015) 651-663. https://doi.org/10.1016/j.cma.2014.09.038

[33] Sheikholeslami, M., Ganji, D.D., Transportation of MHD nanofluid free convection in a porous semi annulus using numerical approach, Chemical Physics Letter 669 (2017) 202-210. https://doi.org/10.1016/j.cplett.2016.12.045

[34] Sheikholeslami, M., Hayat, T., Alsaedi, A., Numerical simulation of nanofluid forced convection heat transfer improvement in existence of magnetic field using lattice Boltzmann method, International Journal of Heat and Mass Transfer - Part B 108 (2017) 1870-1883. https://doi.org/10.1016/j.ijheatmasstransfer.2017.01.044

[35] Sheikholeslami, M., Hayat, T., Alsaedi, A., Numerical study for external magnetic source influence on water based nanofluid convective heat transfer, International Journal of Heat and Mass Transfer 106 (2017) 745-755. https://doi.org/10.1016/j.jiheatmasstransfer.2016.09.077

[36] Sheikholeslami, M., Hayat, T., Alsaedi, A., On simulation of nanofluid radiation and natural convection in an enclosure with elliptical cylinders, International Journal of Heat and Mass Transfer Part A 115 (2017) 981-991. https://doi.org/10.1016/j.ijheatmasstransfer.2017.07.119

[37] Sheikholeslami, M., Hayat, T., Alsaedi, A., Abelman, S., Numerical analysis of EHD nanofluid force convective heat transfer considering electric field dependent viscosity, International Journal of Heat and Mass Transfer - Part B 108 (2017) 2558-2565.

https://doi.org/10.1016/j.ijheatmasstransfer.2016.10.099

[38] Sheikholeslami, M., Rokni, H. B., Melting heat transfer influence on nanofluid flow inside a cavity in existence of magnetic field, International Journal of Heat and Mass Transfer 114 (2017) 517-526. https://doi.org/10.1016/j.ijheatmasstransfer.2017.06.092

[39] Sheikholeslami, M., Rokni, H.B., Nanofluid two phase model analysis in existence of induced magnetic field, International Journal of Heat and Mass Transfer 107 (2017) 288-299. https://doi.org/10.1016/j.ijheatmasstransfer.2016.10.130

[40] Sheikholeslami, M., Rokni, H. B., Simulation of nanofluid heat transfer in presence of magnetic field: A review, International Journal of Heat and Mass Transfer - Part B 115 (2017) 1203-1233. https://doi.org/10.1016/j.ijheatmasstransfer.2017.08.108

[41] Sheikholeslami, M., Sadoughi, M. K., Mesoscopic method for MHD nanofluid flow inside a porous cavity considering various shapes of nanoparticles, International Journal of Heat and Mass Transfer 113 (2017) 106-114. https://doi.org/10.1016/j.ijheatmasstransfer.2017.05.054

[42] Sheikholeslami, M., Seyednezhad, M., Nanofluid heat transfer in a permeable enclosure in presence of variable magnetic field by means of CVFEM, International Journal of Heat and Mass Transfer 114 (2017) 1169-1180. https://doi.org/10.1016/j.jheatmasstransfer.2017.07.018

[43] Sheikholeslami, M., Shehzad, S. A., CVFEM for influence of external magnetic source on $\mathrm{Fe}_{3} \mathrm{O}_{4}$ $\mathrm{H}_{2} \mathrm{O}$ nanofluid behavior in a permeable cavity considering shape effect, International Journal of Heat and Mass Transfer - Part A 115 (2017) 180-191. https://doi.org/10.1016/j.ijheatmasstransfer.2017.07.045

[44] Sheikholeslami, M., Shehzad, S. A., Magnetohydrodynamic nanofluid convection in a porous enclosure considering heat flux boundary condition, International Journal of Heat and Mass Transfer 106 (2017) 1261-1269. https://doi.org/10.1016/j.jheatmasstransfer.2016.10.107

[45] Sheikholeslami, M., Shehzad, S. A., Magnetohydrodynamic nanofluid convective flow in a porous enclosure by means of LBM, International Journal of Heat and Mass Transfer 113 (2017) 796-805. https://doi.org/10.1016/j.ijheatmasstransfer.2017.05.130

[46] Sheikholeslami, M., Shehzad, S. A., Thermal radiation of ferrofluid in existence of Lorentz forces considering variable viscosity, International Journal of Heat and Mass Transfer 109 (2017) 82-92. https://doi.org/10.1016/j.ijheatmasstransfer.2017.01.096 
[47] Siddiqui, A.M., Irum, S., Ansari, A. R., Unsteady squeezing flow of a viscous MHD fluid between parallel plates, Mathematical Modeling and Analysis 13 (2008) 565-576. https://doi.org/10.3846/1392-6292.2008.13.565-576

[48] Sobamowo, M. G., Thermal analysis of longitudinal fin with temperature-dependent properties and internal heat generation using Galerkin's method of weighted residual, Applied Thermal Engineering 99 (2016) 1316-1330. https://doi.org/10.1016/j.applthermaleng.2015.11.076

[49] Wang, C., Analysis of viscous flow due to a stretching sheet with surface slip and suction, Nonlinear Analysis: Real World Applications 10(1) (2009) 375-380. https://doi.org/10.1016/j.nonrwa.2007.09.013

[50] Yao, S., Fang, T., Zhang, Y., Heat transfer of a generalized stretching/shrinking wall problem with convective boundary condition, Communications in Nonlinear science and Numerical simulation 16 (2011) 752-760. https://doi.org/10.1016/j.cnsns.2010.05.028 